\title{
Active trachoma and associated risk factors among children in Baso Liben District of East Gojjam, Ethiopia
}

\author{
Kassahun Ketema ${ }^{1 *}$, Moges Tiruneh$^{2}$, Desalegn Woldeyohannes ${ }^{3}$ and Dagnachew Muluye ${ }^{2}$
}

\begin{abstract}
Background: Trachoma is the leading cause of preventable blindness worldwide. It is common in areas where the people are socio-economically deprived. The aim of this study was to assess active trachoma and associated risk factors among children 1-9 years in East Gojjam.

Methods: Community-based cross-sectional study was conducted in Baso Liben District from February to April 2012. A two-stage random cluster-sampling technique was employed and all children 1-9 years old from each household were clinically assessed for trachoma based on simplified WHO 1983 classification. Data were collected by using semi-structured interview, pre-tested questionnaire and observation. The data were entered and analyzed using SPSS version 16 statistical package.

Results: From a total of 792 children screened for trachoma (of which $50.6 \%$ were girls), the overall prevalence of active trachoma was $24.1 \%$ consisting of only $17.2 \%$ [95\% Cl: 14.8, 20.1] TF and 6.8\% TI. There were variations among children living in low land (29.3\%) and in medium land (21.4\%). In multivariate analysis, low monthly income ( $\mathrm{AOR}=$ adjusted odds ratio) $2.98 ; 95 \% \mathrm{Cl}$ (confidence interval): $1.85-7.85$ ), illiterate family (AOR $=5.18 ; 95 \% \mathrm{Cl}$ : 2.92-9.17); unclean face $(A O R=18.68 ; 95 \% \mathrm{Cl}: 1.98-175.55)$; access to water source ( $\mathrm{AOR}=2.01 ; 95 \% \mathrm{Cl}$ : 1.27-3.15); less than 20 liters of water use ( $A O R=4.88 ; 95 \% \mathrm{Cl}: 1.51-15.78)$; not using soap for face washing ( $A O R=5.84 ; 95 \% \mathrm{Cl}$ : 1.98-17.19); not using latrine frequently $(\mathrm{AOR}=1.75 ; 95 \% \mathrm{Cl}: 0.01-0.42)$; density of flies ( $\mathrm{AOR}=3.77 ; 95 \% \mathrm{Cl}: 2.26-6.29)$; less knowledgeable family $(A O R=3.91 ; 95 \% \mathrm{Cl}: 2.40-6.38)$ and average monthly income (AOR $=2.98 ; 95 \% \mathrm{Cl}: 1.85-7.85)$ were found independently associated with trachoma.
\end{abstract}

Conclusion: Active trachoma is a major public problem among 1-9 years children and significantly associated with a number of risky factors. Improvement in awareness of facial hygiene, environmental conditions, mass antibiotic distribution and health education on trachoma transmission and prevention should be strengthened in the District.

Keywords: Active trachoma, Prevalence, Risk factors, Ethiopia

\section{Background}

Trachoma is a contagious eye infection caused by Chlamydia trachomatis, serovars A, B, Ba or C. [1]. The transmission of trachoma has been known to occur by fomites, direct contact, and eye-seeking fly Musca sorbens which lays its eggs on exposed human feces [2-4]. Communities with endemic trachoma are usually live in dry and dusty area [5] and have been

\footnotetext{
* Correspondence: kasyon33@Gmail.com

${ }^{1}$ Department of Public Health Officer, College of Health Sciences, Debre Markos University, Debre Markos, Ethiopia

Full list of author information is available at the end of the article
}

always associated with poverty, poor sanitation and low socio economic status [6].

Trachoma was eliminated from developed countries through improvements of hygiene and sanitation but still a problem of developing countries [7]. It is endemic in more than 50 countries [8]. According to the WHO (2007) report, globally close to 1.3 million people are blind due to trachoma, while about 84 million people suffer from active trachoma (Trachomatous inflammation, follicular (TF) and/or intense (TI)) [8]. Active infection is mostly seen in young children with a peak incidence of around four to six

\section{Biomed Central}

(c) 2012 Ketema et al.; licensee BioMed Central Ltd. This is an Open Access article distributed under the terms of the Creative Commons Attribution License (http://creativecommons.org/licenses/by/2.0), which permits unrestricted use, distribution, and reproduction in any medium, provided the original work is properly cited. 
years, while subsequent scarring and blindness is seen in adults [9-11].

The national survey (2007) of Ethiopia showed a prevalence of $40.1 \%$ active trachoma among children aged 1-9 years. Amhara region had the highest prevalence of active trachoma among children aged 1-9 years $(62.6 \%)$ and trichiasis in 15 years and above adults (5.2\%) [12]. The high burden of trachoma in the Amhara region calls for collecting a further District-specific data and comprehensive efforts to evaluate the risk factors of trachoma for designing and expanding intervention programs. However, only limited studies were conducted previously, especially on the effect of variation in agroclimates while at present many people in the area are suffering from trachoma in East Gojjam. Among those cases, 64\% were from Baso Liben District (unpublished eye clinic records at Debre Markos referral hospital). With this context, this study determined the prevalence of active trachoma among children in this District and identified risky factors that have paramount importance for the improvement of programs aimed at trachoma prevention and control in the area.

\section{Methods}

\section{Study design}

A community based cross-sectional study was carried out in Baso Liben District, East Gojjam, Amhara Regional state, Ethiopia, from February to April, 2012. Baso Liben District is located on latitude and longitude of $10^{\circ} 09^{\prime} \mathrm{N} 37^{\circ} 45^{\prime} \mathrm{E}$ coordinates: and $10^{\circ} 09^{\prime} \mathrm{N} 37^{\circ} 45^{\prime} \mathrm{E}$ respectively. The area has two agro-climatic divisions: $54 \%$ low land and $46 \%$ medium land with a land of less than 1500 meters and 1500-2500 meters above sea level, respectively. According to the Central Statistical Agency in 2007, Baso Liben District has a total population of 137,470, of whom 67,594 (49.2\%) are men [13]. The number of children aged 1-9 years was about 17,322 [unpublished District health desk information]. The source populations of the study were all children with age of 1-9 years living in Baso Liben District. Five villages of the District were randomly selected as targets of the study. Then children, who met the inclusion criteria from the target villages, were selected as the subjects of the study. Children who had eye injury and/or seriously sick and those who were not at home at the time of study and less than 1 year old were excluded.

\section{Sampling methods}

A total of 792 subjects were enrolled in the study, considering $95 \%$ confidence, $5 \%$ margin of error, design effect of 2, 62.6\% prevalence rate from previous studies [12] and 10\% non-response rate. A two-stage random cluster-sampling technique was employed for selecting the study units. In the first stage, five villages were selected using simple random sampling in order to give equal chance for each village. The number of study participants included in each agro-climate and villages were taken proportionally to their population size. In the second stage, households were selected through a random walk method from each village.

\section{Operational definition}

\section{$\checkmark$}

Active trachoma - Trachomatous inflammation, follicles or Trachomatous inflammation intense.

$\checkmark$

Clean face - a child who did not have an eye discharge or nasal discharge, fly on face at the time of visit.

$\checkmark$

Head of household - the mother or father, who take care of children most of time.

\section{$\checkmark$}

Knowledge: Knowledge questions were calculated after a number of questions were presented. Correct answers were given score 1 and incorrect answers 0 . The sum was computed and those who scored the mean and above were labelled as "knowledgeable" and those who scored below the mean were labelled as "less knowledgeable".

Low land is an area between 1500 and 2000 meters above sea level.

\section{$\checkmark$}

Medium land is an area between 2001 and 2500 meters above sea level.

$\checkmark$

Trachoma negative - children that did not have signs of active trachoma.

\section{$\checkmark$}

Trachomatous inflammation, follicles - Five or more follicles of $>0.5 \mathrm{~mm}$ on the upper tarsal conjunctiva.

\section{Data collection}

Semi-structured questionnaire based interview were used to obtain information on active trachoma. Ten high school students living in the respective villages were trained and interviewed head of the households and observed the children after getting verbal consent from the heads.

Two ophthalmic nurses who had participated in national trachoma survey as eye examiner took part in the examination of the eye. The examination of the eye of each study subjects was done by careful inspection of eye lashes, cornea, limbus, eversion of the upper lid and inspection of the tarsal conjunctiva by the help of magnifying binocular lenses $(x 2.5)$ and penlight torches. The 
guide used for reporting examination results with the simplified trachoma grading scheme was developed by WHO for field work $[12,14]$.

The questionnaires were pre-tested and the necessary corrections were made before the actual data collection. The ophthalmic nurses and data collectors were trained. The principal investigator closely supervised the entire data collection processes. The filled out questionnaires and examination results were collected after checking for consistency and completeness on daily bases. Double entry of $5 \%$ data for checking errors was made.

\section{Data analysis}

Data were entered and analyzed using SPSS version 16 statistical package. The analysis part contains descriptive and inferential statistics. Multivariate logistic regression analysis was also conducted to assess the independent effect of each determinant factor after controlling all other factors. P-value $<0.05$ was considered as statistically significant association.

\section{Ethical considerations}

This study was approved by Ethical review committee of the University of Gondar, College of Medicine and Health sciences, School of Biomedical and Laboratory Sciences. Permission from District administrative office and villages' administrators was obtained. The purpose of the study was explained and verbal consents were obtained from all eligible children's head of households who took part in the study. All children with active trachoma were treated with two tube of tetracycline eye ointment.

\section{Results}

\section{Socio-demographic characteristics}

A total of 792 children aged 1-9 years from 365 households of five villages were systematically selected. The mean \pm standard deviation (SD) age of children was $4.93 \pm 2.35$ years. Of all, $401(50.6 \%)$ were girls and most of the children $540(68.2 \%)$ were preschool age whereas 203(25.6\%) were attending school. Regarding their agro-climatic residential areas there were 273 (34.5\%) and 519 (65.5\%) children from low and medium land villages, respectively. The majority of head of households 252 (69.9\%) were females. Almost all study participants at household level 362 (99.6\%) were Amhara and $362(99.6 \%)$ of them were Orthodox Christians. Three hundred eleven (85.2\%) of respondents were farmers. Two hundred nineteen $(60 \%)$ of heads of households were illiterate while $146(40 \%)$ had attended primary school and above. The average monthly income of most households 443 (55.9\%) was less than or equal to 600 Ethiopian birr (ETB). The average family size among the population was 5.43 (Table 1).
Table 1 Socio-demographic characteristics of heads of household in Baso Liben District from February to April, 2012

\begin{tabular}{lcc}
\hline Characteristics & Frequency $(\mathbf{N}=\mathbf{3 6 5})$ & Percentage (\%) \\
\hline Sex of head of household & 110 & 30.1 \\
Male & 255 & 69.9 \\
Female & & \\
Age in years & 170 & 46.6 \\
18-29 & 134 & 36.7 \\
$30-44$ & 41 & 11.2 \\
$45-59$ & 20 & 5.5 \\
$60+$ & & \\
Occupation & 311 & 85.2 \\
Farmer & 33 & 9.1 \\
Merchant & 21 & 5.7 \\
Others & & \\
Education status & 219 & 60 \\
Illiterate & 146 & 40 \\
Primary and above & & 5.4 \\
Average Monthly income & 443 & 30.2 \\
$<600$ & 239 & 9.5 \\
$601-1200$ & 75 & \\
1201-2000 & 35 & \\
$>2000$ & & \\
\hline & &
\end{tabular}

\section{Active trachoma among children of 1-9 years old}

The overall prevalence of active trachoma was 191 (24.1\%). Of these, $137(17.2 \%)$ were TF cases while 54 (6.9\%) were TI cases (Figure 1). Among all cases of TI, $29(53.1 \%)$ were girls. The proportion across the ages increases reaching peak of $34(27.9 \%)$ at the age 4 years and slowly decreases as age increases. There were agroclimatic residence area variations in the active trachoma among children which was 80 (29.3\%) in low land and $111(21.4 \%)$ in the medium. Moreover, TF and TI were more common [(20.1\% versus $9.5 \%)$ in low land relative

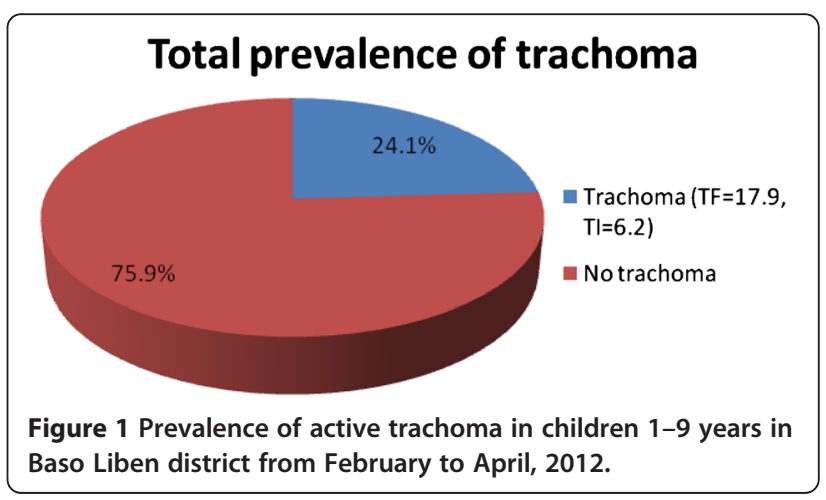


to $(16.8 \%$ versus $4.4 \%)$ in medium land respectively] (Figure 2). Number of illiterate household heads in low land were 208 (76.2\%) and 267 (51.4\%) in medium land; $53.8 \%$ households have no latrine in low land but only $27.4 \%$ in medium land; more flies on face of children $9.5 \%$ were in low land and $3.1 \%$ in medium land. Most of household heads 192 (70.5\%) of low land have less knowledge on trachoma while 323 (62.2\%) in medium land. Number of illiterate household heads, absence of latrine and presence of more flies on the face of children were found statistically significant for agro-climatic area variations.

The distribution of active trachoma was different in different age groups. TF was very high at the age one and four years. Among age groups, 4-6 years old children $84(10.6 \%)$ were more infected than $1-3$ years old (7.3\%) and 7-9 years old (6.2\%) children.

\section{Factors associated with active trachoma}

In multivariate analysis; proxy indicators of low socioeconomic status, educational status of households, access to water source, amount of water consumption per capita, frequency of latrine usage, usage of soap, unclean face, number of fly on face of a child and awareness status of households on trachoma were found independently associated with active trachoma.

Children from illiterate heads of households 170 (35.8\%) were 5 times $(\mathrm{AOR}=5.19 ; 95 \%$ CI 2.93-9.18) more likely to have active trachoma than those from educated ones 21 (6.6\%). The prevalence of trachoma infection decreases from $148(18.7 \%)$ to $0(0 \%)$ as average monthly income of their family increases from less than or equal to 600 to greater than 2000 ETB $(\mathrm{AOR}=2.98$; 95\% CI 1.86-7.86). The prevalence of active trachoma among girls (24.7\%) and boys (23.5\%) was almost similar. More children from households having water access in more than 30 minutes distance 111 (35.7\%) were found with active trachoma than those who could access water within 30 minutes or less foot travel distance 80 (16.6\%) $(\mathrm{AOR}=2.008 ; 95 \% \mathrm{CI} 1.28-3.16)$. The prevalence of active trachoma was also high in children from parents with average daily water consumption of 2-4 liters/ capita, 313 (39.5\%) than those having more than 8 liters/ capita 59 (7.4\%) (AOR $=5.45 ; 95 \%$ CI 1.85-16.02). The common sources of water for domestic consumption in the study area were river 447 (56.4\%), tap water 201 (25.4\%) and other sources 144 (18.2\%). Active trachoma was more prevalent in children who did not frequently wash their face 7 (31.8\%) than those who washed their face more than once per day $22(11.1 \%)$ (AOR $=5.84$; 95\% CI 1.98-17.19). Children with unclean face were about 18 times more likely to have active trachoma than those with clean faces (Table 2).

Most of the children from households who claimed using latrine always had less chance of developing infection compared to those using latrine occasionally and it was statistically significant. The prevalence of active trachoma among children from households with less awareness about trachoma were about four times more likely to develop trachoma compared to those from knowledgeable families $(\mathrm{AOR}=3.92$; 95\% CI 2.41-6.38) (Table 2).

\section{Discussion}

The findings of this study showed overall prevalence of 24.1\% active trachoma (range, 21.4-29.3\%). Even if it is decreasing in figure compared to Amhara regional prevalence, $62.2 \%$ in 2007 [15], the finding of the study confirmed that trachoma is still a disease of public health interest. This result was almost in agreement with studies in other countries like in Malawi, 25.1\% (16). The possible explanation could be increment of mass antibiotic distribution coverage with weak integration of health promotion on primary eye care, health information on

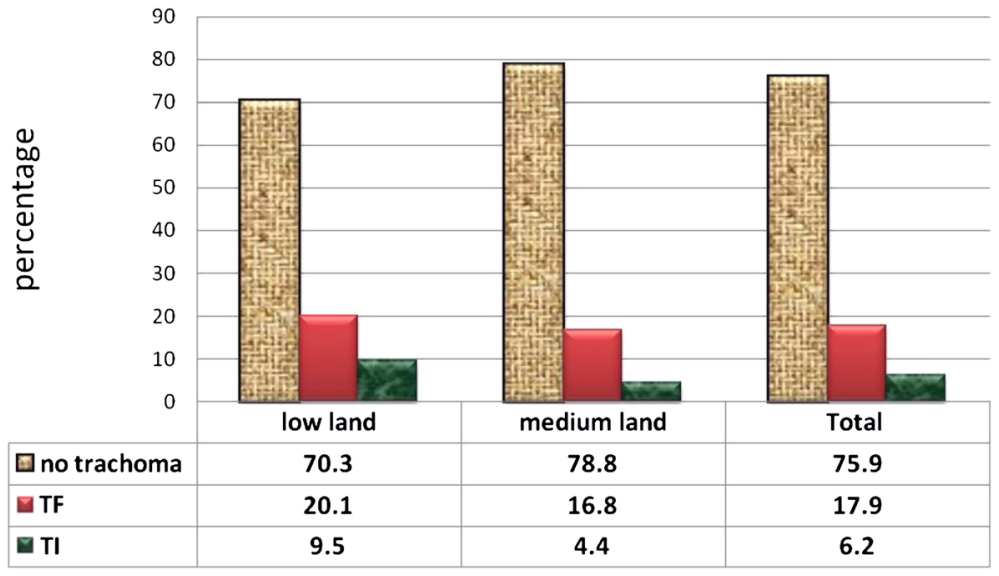

Figure 2 Prevalence of active trachoma in study subjects in low land and medium land in Baso Liben District from February to April, 2012. 
Table 2 Association of active trachoma and potential risk factors among children 1-9 years in Baso Liben District from February to April, 2012

\begin{tabular}{|c|c|c|c|c|}
\hline \multirow[t]{2}{*}{ Characteristics } & \multicolumn{2}{|l|}{ Trachoma status } & \multirow[t]{2}{*}{ Crude OR $(95 \% \mathrm{Cl})$} & \multirow[t]{2}{*}{ Adjusted OR $(95 \% \mathrm{Cl}$} \\
\hline & Total examined $\mathrm{N}(\%)$ & Positive N (\%) & & \\
\hline \multicolumn{5}{|l|}{ Agro-climate } \\
\hline Low land & $273(34.5)$ & $80(29.3)$ & $1.52(1.09-2.12)^{*}$ & $1.12(0.58-2.16)$ \\
\hline Medium land & $519(65.5)$ & $111(21.4)$ & 1 & \\
\hline \multicolumn{5}{|c|}{ Educational status of head of household } \\
\hline Illiterate & 219(59.2) & 78(35.8) & $7.85(4.85-12.70)^{* * *}$ & $5.18(2.93-9.17)^{* * *}$ \\
\hline primary\& above & 146(40.8) & $10(6.6)$ & 1 & \\
\hline \multicolumn{5}{|l|}{ Average monthly income } \\
\hline$<600$ & $443(55.9)$ & $148(18.7)$ & $4.60(2.81-7.53)^{* * *}$ & $2.98(1.85-7.85)^{* * *}$ \\
\hline $601-1200$ & 239(30.2) & $41(5.2)$ & $2.37(1.37-4.09)$ & $3.89(1.87-8.09)$ \\
\hline $1201-2000$ & $75(9.5)$ & $2(0.3)$ & $1.01(.53-1.93)$ & $1.29(0.56-3.81)$ \\
\hline$>2000$ & $35(4.4)$ & $0(0)$ & 1 & \\
\hline \multicolumn{5}{|l|}{ Access to water source } \\
\hline$\leq 30$ minutes walk away & $729(92)$ & 209(28.7) & 1 & \\
\hline$>30$ minutes walk away & $63(8)$ & $8(12.7)$ & $2.78(1.99-3.88)^{* * *}$ & $2.01(1.27-3.15)^{* *}$ \\
\hline \multicolumn{5}{|c|}{ Daily average Water consumption } \\
\hline$<20$ liters per head & $160(20.2)$ & $41(25.60$ & $2.55(1.07-6.08)^{* * *}$ & $4.88(1.51-15.78)^{* *}$ \\
\hline 20-40 liters per head & $313(39.5)$ & 100(31.9) & $3.48(1.53-7.55)$ & $5.45(1.85-16.01)$ \\
\hline 40-60 liters per head & 152(19.2) & 18(11.8) & $0.99(0.39-0.2 .52)$ & $1.46(.451-4.77)$ \\
\hline 60-80 liters per head & 108(13.6) & $25(23.1)$ & $2.23(0.90-5.54)$ & $2.37(.72-7.74)$ \\
\hline$>80$ I per head & $59(7.5)$ & $7(11.9)$ & 1 & \\
\hline \multicolumn{5}{|l|}{ Frequency of larine usage } \\
\hline Always & $387(76.7)$ & $39(10.1)$ & 1 & \\
\hline Sometimes & $117(23.3)$ & $53(45.3)$ & $1.58(0.14-0.32)^{* * *}$ & $1.75(0.12-0.42)^{* *}$ \\
\hline \multicolumn{5}{|l|}{ Usage of soap } \\
\hline Yes & $250(31.5)$ & $22(8.8)$ & 1 & \\
\hline No & $542(68.5)$ & 169(31.2) & $4.69(2.92-7.54)^{* * *}$ & $5.84(1.98-17.19)^{* *}$ \\
\hline \multicolumn{5}{|l|}{ Clean face of child } \\
\hline Clean face & $46(5.8)$ & $1(2.2)$ & 1 & \\
\hline Unclean face & $746(94.2)$ & $190(25.5)$ & $15.37(2.10-11.32)^{* *}$ & $18.68(1.98-175.55)^{*}$ \\
\hline \multicolumn{5}{|c|}{ Number of fly on face of child } \\
\hline $0-3$ & $546(69.9)$ & 73(13.4) & 1 & \\
\hline $4-7$ & 204(25.7) & $94(46.1)$ & $5.53(3.82-8.01)^{* * *}$ & $3.77(2.26-6.29)^{* *}$ \\
\hline$>7$ & $42(5.3)$ & $24(57.5)$ & $8.63(4.47-16.69)$ & $4.47(1.86-10.70)$ \\
\hline \multicolumn{5}{|c|}{ Knowledge of heads of household } \\
\hline Knowledgeable & $188(51.5)$ & $30(16.6)$ & 1 & \\
\hline Less knowledge & $177(48.5)$ & $57(32.1)$ & $2.37(1.69-3.32)^{* * *}$ & $3.91(2.40-6.38)^{* * *}$ \\
\hline
\end{tabular}

***Significant at $p$-value $\leq 0.001,{ }^{* *}$ significant at $p$-value $\leq 0.01,{ }^{*}$ significant at $p$-value $\leq 0.05$.

personal and environmental hygiene of the Districts. The prevalence was higher than the study in Ghana (16.1\%) [16]. This might be due to differences in endemicity and period of study.

The prevalence of active trachoma was higher in lowland than medium land agro-climatic residence area.
The potential risk factors related to agro-climatic area differences were illiterate household heads, absence of latrine, more flies on face of children. Children from illiterate household heads were 5 times more likely to have active trachoma than from literate household heads. This result was consistent with a study conducted 
in Tigray region, Ethiopia [17]. Similar finding was reported from Tanzania [18]. These might be due to the effect of literacy of the father/mother which is especially important because she/he is responsible for the caretaking of the children. An educated mother may be more aware of the benefits of hygiene practices to the health of her children compared to an uneducated mother.

Children from households getting less monthly income were more likely to have trachoma than those from households getting more income. A similar outcome was reported in Ethiopia [6]. The possible explanation could be due to effects of poverty on health care, lack of hygiene, high chance of sharing tools, immunity status, and lack of information.

Those families who walk more than 30 minutes distance from water source were two times more likely to have trachoma than those on less than 30 minutes walk from water bodies. This finding was in line with investigations of Tanzania and Ethiopia [19-21].

The study has also revealed more association between active trachoma and frequency of latrine use than presence of latrine. This result is similar with previous report in Ankober, Ethiopia [21]. This could be due to inaccessibility to latrine facilities and frequent exposed of human feces which are risk factors for the presence of high number of fly-eyes that leads to high chance of transmission of trachoma.

In the present study, there was significant association between active trachoma and unclean face. This finding is similar to studies that identify the presence of ocular and nasal discharge as risk factors for the presence of fly on eyes and active trachoma in Ethiopia and Tanzania $[18,22]$. The presence of more flies on face was associated with more chance of having active trachoma. This finding is consistent with different investigations in Brazil; Nigeria and Ethiopia [23-25]. The possible explanation could be the role of eye seeking fly in trachoma transmission which is still remained common and high.

Children with less knowledgeable household heads about trachoma had about four times more likely to have infection than children from knowledgeable household heads. This finding was in line with investigations in Ethiopia which also reported overall reduction of trachoma ranges from $4 \%$ to $12 \%$ after provision of health education for community [26,27]. Similar result was reported by the study conducted in Tanzania on comparing effect of antibiotic treatment alone versus antibiotic treatment combined with an intensive health education programme about facial cleanliness [28]. The possible explanation for the differences could be less access to information, education and communication media on trachoma prevention, community based health education by trained health workers or volunteers and eye care units in the District.
The limitation of the study were the estimation of economic status, distance of water source and average monthly income of study households. It was merely based on respondents' reply to the interviewer questions, which may be uncertain. Due to lack of sufficient resources the positive result of trachoma status could not be confirmed by advanced laboratory tests so that differential diagnosis may exaggerate the result. Moreover, the small sample size used might have an effect on the real magnitude of active trachoma.

\section{Conclusion}

The prevalence of active trachoma among children 1-9 years old in Baso Liben District exceeds the WHO guidelines for the intervention with mass antibiotic distribution which warrants the trachoma SAFE control strategy to be strengthened in the District. A number of risky factors were significantly associated with prevalence of active trachoma. These include low socioeconomic and/or educational status of heads of households, distance of water source from home, average water consumption, frequency of usage latrine and soap among others. Unclean face, density of fly on face of a child and awareness of head of households about trachoma were also determinant factors for the occurrence of active trachoma. Access to sanitary water and frequently using latrines are essential factors of the ' $E$ ' component of the SAFE strategy. Moreover, there was higher prevalence of active trachoma in low land than medium land villages that needs special attention in preventive programs.

\section{Competing interests}

The authors declare that they have no competing interests.

\section{Authors' contributions}

KK: conception and initiation of the study, design, implementation, analysis and writing. MT: design, implementation of the study and co-writing. DW: design, implementation and co-writing. DM: design, implementation, analysis and co-writing. All authors read and approved the final manuscript.

\section{Acknowledgements}

We acknowledge the financial and technical support provided by the School of Biomedical and Laboratory Sciences, College of Medicine and Health Sciences, University of Gondar. The support obtained from Amhara Regional Health Bureau, East Gojjam Zone Health Desk, Baso Liben District's health office, data collectors and all the study participants were highly acknowledged. We are deeply indebted to Dr. Yilikal Alemu and eye unit staff members of Debre Markos referral hospital for their constructive comments, provision of different materials and participating in data collection.

\section{Author details}

${ }^{1}$ Department of Public Health Officer, College of Health Sciences, Debre Markos University, Debre Markos, Ethiopia. ${ }^{2}$ School of Biomedical and Laboratory Sciences, College of Medicine and Health Sciences, University of Gondar, Gondar, Ethiopia. ${ }^{3}$ Department of Public Health, School of Medicine and Health Sciences, Addis Ababa Science and Technology University, Ethiopia. 
Received: 4 July 2012 Accepted: 16 November 2012

Published: 22 December 2012

\section{References}

1. Pascolini D, Mariotti SPM: Global estimates of visual impairment: 2010. Ophthalmology: British Journal; 2011.

2. Wright H, Turner A, Taylor H: Trachoma. Lancet 2008, 371:1945-1954.

3. Emerson PM, Bailey RL, Walraven GE, Lindsay SW: Human and other faeces as breeding media of the trachoma vector Musca sorbens. Med Vet Entomol 2001, 15:314-320.

4. Alemayehu W, Melese M, Fredlander E, Worku A, Courtright P: Active trachoma in children in central Ethiopia: association with land. Trans $R$ Soc Trop Med Hyg 2005, 99:840-843.

5. World Health Organization Global Elimination of Blinding Trachoma: World health organization 51st world health assembly resolution 51.11. Geneva: WHO; 1998.

6. Zerihun N: Impact of trachoma among rural Ethiopian women. Ethiop J Health sciences 1998, 8:53-59.

7. Mecaskey JW, Knirsch CA, Kumaresan JA, Cook JA: The possibility of eliminating blinding trachoma. Lancet Infect Dis 2003, 3:728-734.

8. Burton MJ, Mabey DCW: The global burden of trachoma: a review. PLOS Negl Trop Dis 2009, 10:e460.

9. Schwab L, Whitfield R, Ross-Degnan D, Steinkuller P, Swartwood J: The epidemiology of trachoma in rural Kenya. Variation in prevalence with lifestyle and environment. Study survey group. Ophthalmology 1995 102:475-482.

10. West $S$, Nguyen MP, Mkocha $H$, Holdsworth $G$, Ngirwamungu E, Kilima $P$, Munoz B: Gender equity and trichiasis surgery in the Vietnam and Tanzania national trachoma control programmes. Br J Ophthalmol 2004, 88:1368-1371.

11. Turner VM, West SK, Muñoz B, Katala SJ, Taylor HR, Halsey N, Mmbaga BBO Risk factors for trichiasis in women in Kongwa, Tanzania: a case-contro study. Int J Epidemol 1993, 22:341-347.

12. Berhane $Y$, Worku A, Bejiga A, Liknaw A, Wondu A, Badri A, Haile Z, Ayalew A, Adamu Y, GETBe T, Kebede TD, West E, West $S$ : Prevalence and causes of blindness and Low vision in Ethiopia. Ethiop J Health Dev 2007, 21:211-215.

13. Baso Liben (woreda) - Wikipedia, the free encyclopedia. 2012. Available on http://en.wikipedia.org/wiki/BasoLiben (woreda). Accessed on 16 January.

14. World Health Organization: Primary health care level management of trachoma. Geneva: WHO; [WHO/PBL/93.33]; 1993.

15. Ngondia J, GETBec T, Shargiec EB, Gravesa PM, Ejigsemahuc Y, Teferi T, Genetd A, Moshera AW, Endeshaw T, Zerihun M, Messele A, Richards FO, Emersona PM: Risk factors for active trachoma in children and trichiasis in adults: a household survey in Amhara Regional State, Ethiopia. Trans $R$ Soc Trop Med Hyg 2008, 102:432-438.

16. World Health Organization: Report of the six meeting of the WHO alliance for the global elimination of blinding trachoma. Geneva, Switzerland: WHO/PBD/ GET/02.1; 2001.

17. Mesfin MM, de la Camera J, Tareke IG, Amanual G, Araya T, Kadir AM: A community-based trachoma survey: prevalence and risk factors in the Tigray region of northern Ethiopia. Ophthalmic Epidemio/ 2006, 13:173-181.

18. Harding-Esch EM, Edwards T, Mkocha H, Munoz B, Holland MJ, Burr SE, Sillah A, Gaydos CA, Mabey DCW, Bailey RL, West SK: Trachoma prevalence and associated risk factors in the Gambia and Tanzania: baseline results of a cluster randomised controlled trial. PLoS Negl Trop Dis 2010, 4:861.

19. Baggaley RF, Solomon AW, Kuper H, Polack S, Massae PA, Kelly J, Safari S, Alexander NE, Courtright P, Foster A, Mabey DC: Distance to water source and land in relation to active trachoma in Rombo District Tanzania. Trop Med Int Health 2006, 11:220-227.

20. Polack S, Kuper H, Solomon AW, Massae PA, Abuelo C, Cameron E, Valdmanis $V$, Mahande M, Foster A, Mabey D: The relationship between prevalence of active trachoma, water availability and its use in a Tanzanian village. Trans R Soc Trop Med Hyg 2006, 100:1075-1083.

21. Golovaty I, Jones L, Gelaye B, Tilahun M: Access to water source, latrine facilities and other risk factors of active trachoma in ankober. Ethiopia. PLoS One 2009, 4:e6702.

22. Edwards T, Harding-Esch EM, Hailu G, Andreason A: Risk factors for active trachoma and Chlamydia trachomatis infection in rural Ethiopia after mass treatment with azithromycin. Trop Med Int Health 2008, 13:556-565.
23. Reilly LA, Favacho J, Garcez LM, Courtenay O: Preliminary evidence that synanthropic flies contribute to the transmission of trachoma causing Chlamydia trachomatis in Latin America. 23rd edition. Rio de Janeiro: Cad. Saúde Pública; 2007:1682-1688.

24. Mpyet C, Goyol M, Ogoshi C: Personal and environmental risk factors for active trachoma in children in Yobe state, north-eastern Nigeria. Trop Med Int Health 2010, 15:168-172.

25. Cumberland $P$, Hailu G, Todd J: Active trachoma in children aged three to nine years in rural communities in Ethiopia: prevalence, indicators and risk factors. Trans R Soc Trop Med Hyg 2005, 99:120-127.

26. Cumberland P, Edwards T, Hailu G, Harding-Esch E, Andreasen A, Mabey D, Todd J: The impact of community level treatment and preventative interventions on trachoma prevalence in rural Ethiopia. Int J Epidemio 2008, 37:549-558.

27. Edwards T, Cumberland PH, Hailu G, Todd J: Impact of health education on active trachoma in hyperendemic rural communities in Ethiopia. Ophthalmology 2006, 113:548-555.

28. West S, Muñoz B, Lynch M, Kayongoya A, Chilangwa Z, Mmbaga BBO, Toyler HR: Impact of face-washing on trachoma in Kongwa Tanzania. Lancet 1995, 345:155-158.

\section{doi:10.1186/1471-2458-12-1105}

Cite this article as: Ketema et al:: Active trachoma and associated risk factors among children in Baso Liben District of East Gojjam, Ethiopia. BMC Public Health 2012 12:1105

\section{Submit your next manuscript to BioMed Central and take full advantage of:}

- Convenient online submission

- Thorough peer review

- No space constraints or color figure charges

- Immediate publication on acceptance

- Inclusion in PubMed, CAS, Scopus and Google Scholar

- Research which is freely available for redistribution

Submit your manuscript at www.biomedcentral.com/submit
C Biomed Central 